\title{
Rotating Electrical Machine Condition Monitoring Automation-A Review
}

\author{
Mallikarjun Kande ${ }^{1,2, *,+}$, Alf J. Isaksson ${ }^{3}$, Rajeev Thottappillil ${ }^{1}$ (iD and Nathaniel Taylor $^{1}$ (ID \\ KTH—Royal Institute of Technology, 10044 Stockholm, Sweden; rajeev@kth.se (R.T.); taylor@kth.se (N.T.) \\ ABB Power Generation, Wickliffe, OH 44092, USA \\ 3 ABB Corporate Research, 72178 Västerås, Sweden; alf.isaksson@se.abb.com \\ * Correspondence: mskande@kth.se \\ † Current address: 29801 Euclid Ave, Wickliffe, OH 44092, USA.
}

Received: 25 August 2017; Accepted: 13 October 2017; Published: 19 October 2017

\begin{abstract}
We review existing machine condition monitoring techniques and industrial automation for plant-wide condition monitoring of rotating electrical machines. Cost and complexity of a condition monitoring system increase with the number of measurements, so extensive condition monitoring is currently mainly restricted to the situations where the consequences of poor availability, yield or quality are so severe that they clearly justify the investment in monitoring. There are challenges to obtaining plant-wide monitoring that includes even small machines and non-critical applications. One of the major inhibiting factors is the ratio of condition monitoring cost to equipment cost, which is crucial to the acceptance of using monitoring to guide maintenance for a large fleet of electrical machinery. Ongoing developments in sensing, communication and computation for industrial automation may greatly extend the set of machines for which extensive monitoring is viable.
\end{abstract}

Keywords: condition monitoring; rotating electrical machine; motor fleet; plant-wide

\section{Introduction}

Condition Monitoring (CM) is a process of acquiring equipment health status and predicting the operational ability of a system in a given environment: the health of the system is evaluated during its operation, and possible failures associated with it are recognized at an early stage. Motivations for condition monitoring $(\mathrm{CM})$ in industrial automation include reductions in downtime, maintenance activity and related faults, and increases in energy efficiency, yield, and quality. Predictive diagnostics based on CM permit a well-informed plant maintenance activity. Condition based maintenance (CBM) using the equipment condition assessment has several benefits as compared to scheduled cyclic or reactive plant maintenance, mainly in terms of reduced downtime and replacement cost [1]. The methods used in system health assessment depend on plant infrastructure, operational criticality, process work flow, and ease of repair and service. A cost effective CBM can in some cases be achieved even with low cost condition monitoring equipment, for example by statistical treatment to reduce false positives and negatives in spite of the uncertainty of measurements or fault-trigger thresholds [2]. The success of CBM depends on the overall cost of the condition monitoring system in a plant, its arrangement, and on the relative benefits compared to the operation and maintenance costs over the life of the plant.

The infrastructure chain in the power and process industries commonly has power generation, substation, power distribution, process control and plant operation equipment. Most of these subsystems are integrated with the distributed control system (DCS) and can publish their health status periodically for predictive diagnostics. The successful deployment of condition monitoring in process and power industries also relies upon the combined analysis of interrelated elements, such as structural, stochastic, resource, economic, etc, [3]. Generators, motors, turbines, and other rotating 
electrical machines are usually distributed in large numbers across the plant. The monitoring of the distributed rotating electrical machines such as smart motors sending fault information wirelessly may demand modification of the legacy CM practices. This paper reviews the traditional condition monitoring techniques, recent activities, and deployment of the intelligent machines in an industrial automation system. It covers the evolution and recent trends regarding rotating electrical machines, as well as deployment use case for plant-wide operations and future directions.

\section{Machine Condition Monitoring: An Evolution}

One of the first references to machine condition monitoring can be found in 1924 by Walker [4], who proposed a measurement system that used data and theoretically based analysis for diagnosis of motor faults. Vibration analysis for machine diagnosis started about 1950 [5], with accelerometers proposed in place of magnetic velocity pickup, besides development of vibration and temperature pick-ups, spectrum analysis, and computer-based diagnostic applications. Another important proposal was to use non-contacting vibration pick-ups: non-contact sensors for condition monitoring applications proposed during this period did not gain popularity due to technical limitations of sensors, cabling, and data acquisition electronics [5]. Partial discharge (PD) measurements have been widely used to detect insulation faults in machines above the low-voltage level. These have been correlated with types of insulation degradation for early warning of developing problems [6]. During the 1980s, Timperley showed that a combination of 'electromagnetic interference' measured at the neutral of an operating machine, together with wideband spectrum analysis, can provide significant diagnostic information with long lead time before complete failure [7].

The importance of monitoring systems that operate without shutdown of the machine (i.e., online) was further emphasized in [8], in which the benefits of daily monitoring of machines are shown through radio frequency $(\mathrm{RF})$ measurements at the machine neutral using permanently installed RF sensors. The maturity of adjacent technologies during 2000 to 2010 in the area of sensing, digital data acquisition and integration of communication equipment has shown the increasing viability of continuous monitoring. The practitioners have made an effort to prove that the continuous diagnostics with real-time update of the plant-wide machine condition increases business profit through informed maintenance and service decisions $[9,10]$. The development of an integrated system prompted industries to use condition based maintenance through continuous assessment of equipment health across the plant. During the past three decades, there has been a steady growth in machine condition monitoring technologies owing to its importance concerning plant safety and mission criticality. Monitoring methods have been matured giving raise to the adaptation of reliable CM systems for fault prediction, detection, and fault location identification for various types of rotating machines in the plant's system critical chain.

Long service life, low cost, and useful fault indication are some of the most important aspects for the evolution of condition monitoring systems. The driving factors for this evolution are as given below:

- Efficient maintenance and reliable operation: accurate detection of incipient faults with sufficient lead time; thus, evolutions of health monitoring technologies are motivated by the increased productivity and/or reduced investments for maintenance.

- Maximized overall profitability: the monitoring technologies should have a low cost, to the point where further reduction would deteriorate the monitoring quality significantly.

- A sustainable business based on reliable monitoring systems whose service life equals that of the monitored equipment and at the same time offers lower total operating cost.

Figure 1 shows the condition monitoring technology trends that evolved over the years aligning to the plant life cycle functions. The plant life cycle can have five most important phases: (i) maintenance and service plans for developing the case for the use of condition monitoring in the plant; (ii) commissioning to deploy the monitoring applications; (iii) engineering to configure 
the system elements; (iv) plant operations for setting the human-machine interface (HMI) views, thresholds, and generating actions for maintenance, and (v) maintenance and service activities for keeping the main stream equipment in healthy conditions for its long and precise working [11].

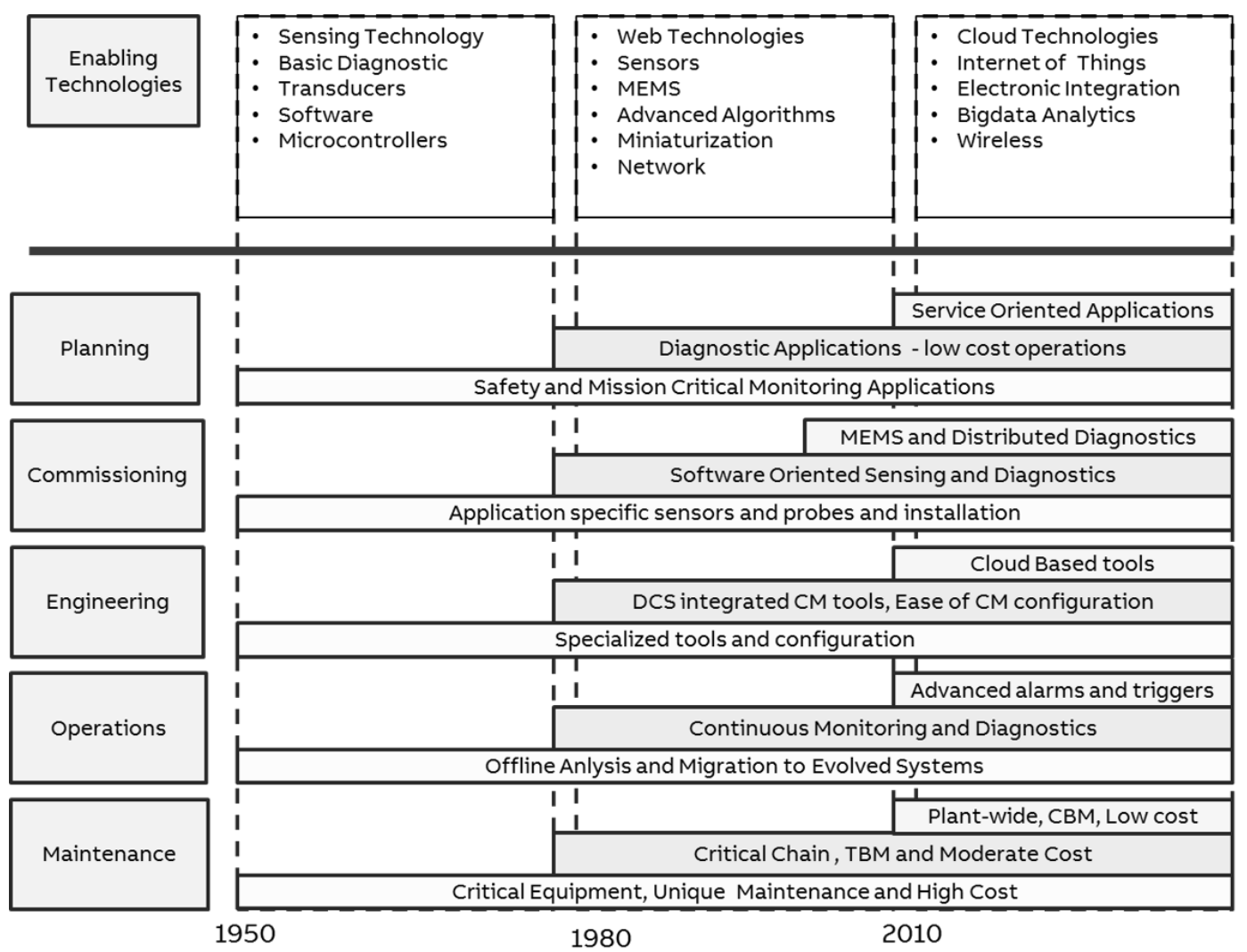

Figure 1. Technology trends, plant life cycle and monitoring system evolution.

Each phase has its technical challenges for employing condition monitoring solutions for rotating electrical machines. The planning phase deals with selection of the monitoring and the diagnostic applications based on the customer end use requirements. The rotating machine diagnostic applications are largely focused on detection of bearing and insulation failures using thermal, vibration, acoustic, magnetic, and partial discharge sensors. Identification of the correct sensor combination and corresponding diagnostic algorithms that can completely meet the end use application is one of the biggest challenges. The survey conducted addresses the steady growth that has been established in diagnostic algorithms and associated elements in areas of the rotating machine monitoring. The related challenges associated with these elements, such as sensor mounting and compensation, data acquisition, computation capability, etc., are assessed with regard to condition monitoring applications. For example, micro electro-mechanical sensors (MEMS) may bring down the costs, provided they exhibit long-term stability and reliable functioning throughout the service life of the equipment. During commissioning, it is vital to have a convenient setup for the hardware and software: this includes the installation of a measurement system that consists of sensors, sensor mount, data acquisition units, a communication unit, etc. The system configuration and architecture influence the monitoring cost per point. Hence, it is necessary to optimize the measurement, communication, and distribution of processing algorithm at various levels, in order to meet the monitoring application specifications $[12,13]$. The engineering phase is mainly related to configuring the system for its functionality; the greatest challenge is getting unified tools that can work along with the automation system native tools. Operation related activities are mainly related to maintaining the condition monitoring system, performing information acquisition, and running the diagnostics expert system for 
fault predictions. This system continuously updates the information related to early failures during the plant operations [14].

Condition based maintenance (CBM) in industrial automation has evolved to achieve reduction of maintenance effort and time. The challenges are the optimization of maintenance work flow, information system, timely maintenance, and equipment service. Various elements within the maintenance process are shown in Figure 2. The process optimization includes minimizing the activities associated with managing the measurement system, information system and maintenance work flow. It is also necessary to reduce time between a maintenance trigger and equipment service or repair or replacement, which is efficient enough to justify the condition monitoring investments [15].

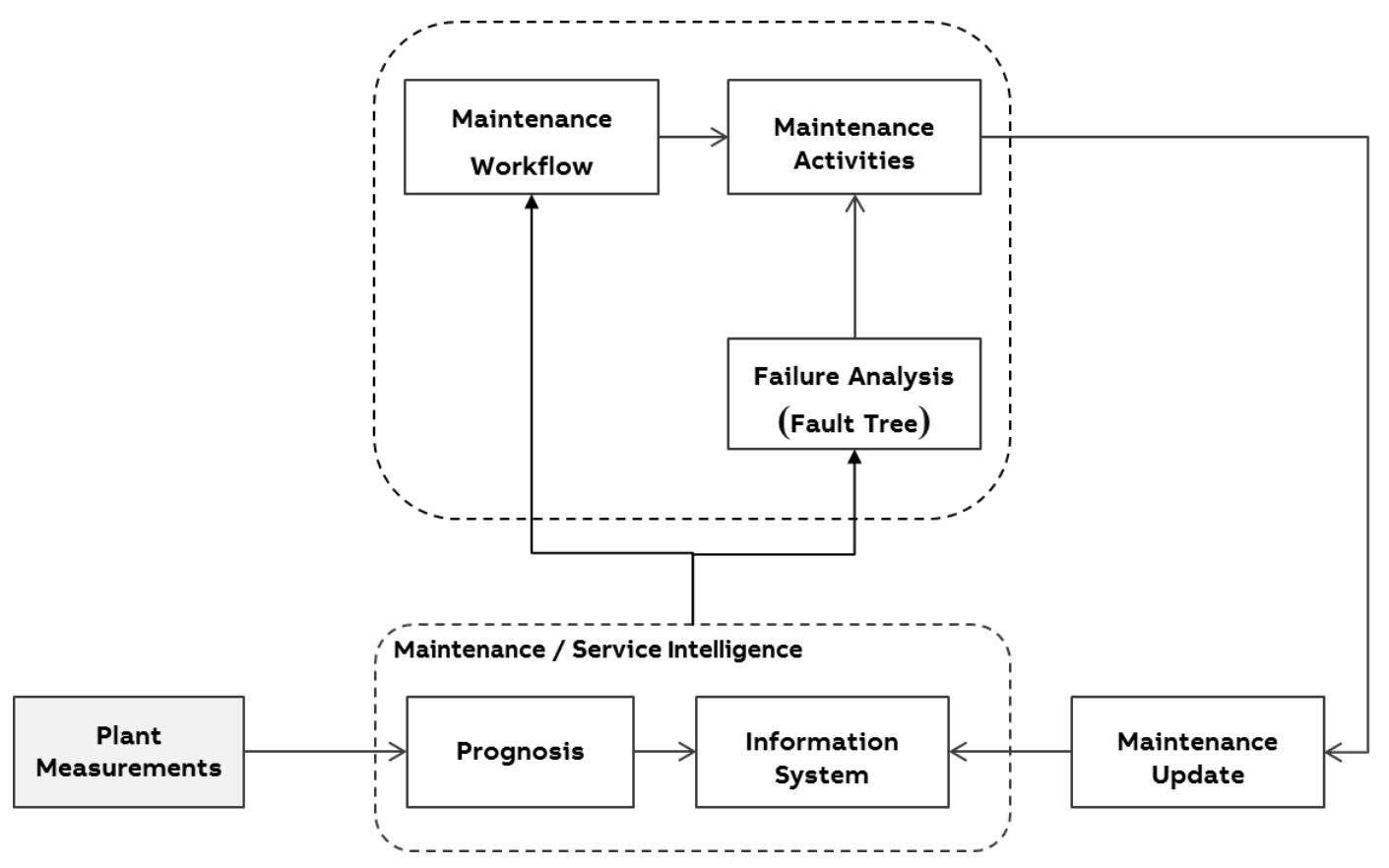

Figure 2. Condition based plant maintenance process.

Business models for condition monitoring evolved from a selective equipment monitoring to plant-wide diagnostics of all the dependent subsystems, i.e., a fleet of machines across the plant. The decision of using a condition monitoring system in the plant is mostly based on the trade-off between the risks associated with equipment failure and number of check points [16]. Recent trends show integration of monitoring functions with process control, leading to the development of suitable platforms, in particular smart sensors and related application software.

Figure 3 represents a typical process flow diagram for the plant-wide machine monitoring system. This type of deployment needs multi-point measurement, changing the economic scale of sensors required for machine condition monitoring. If the monitored device is in the critical chain, then the decision to employ health monitoring could be easy; if not, cost per monitoring point needs to be justified concerning business returns associated with machine maintenance, service revenue, product quality, and yield [17]. 


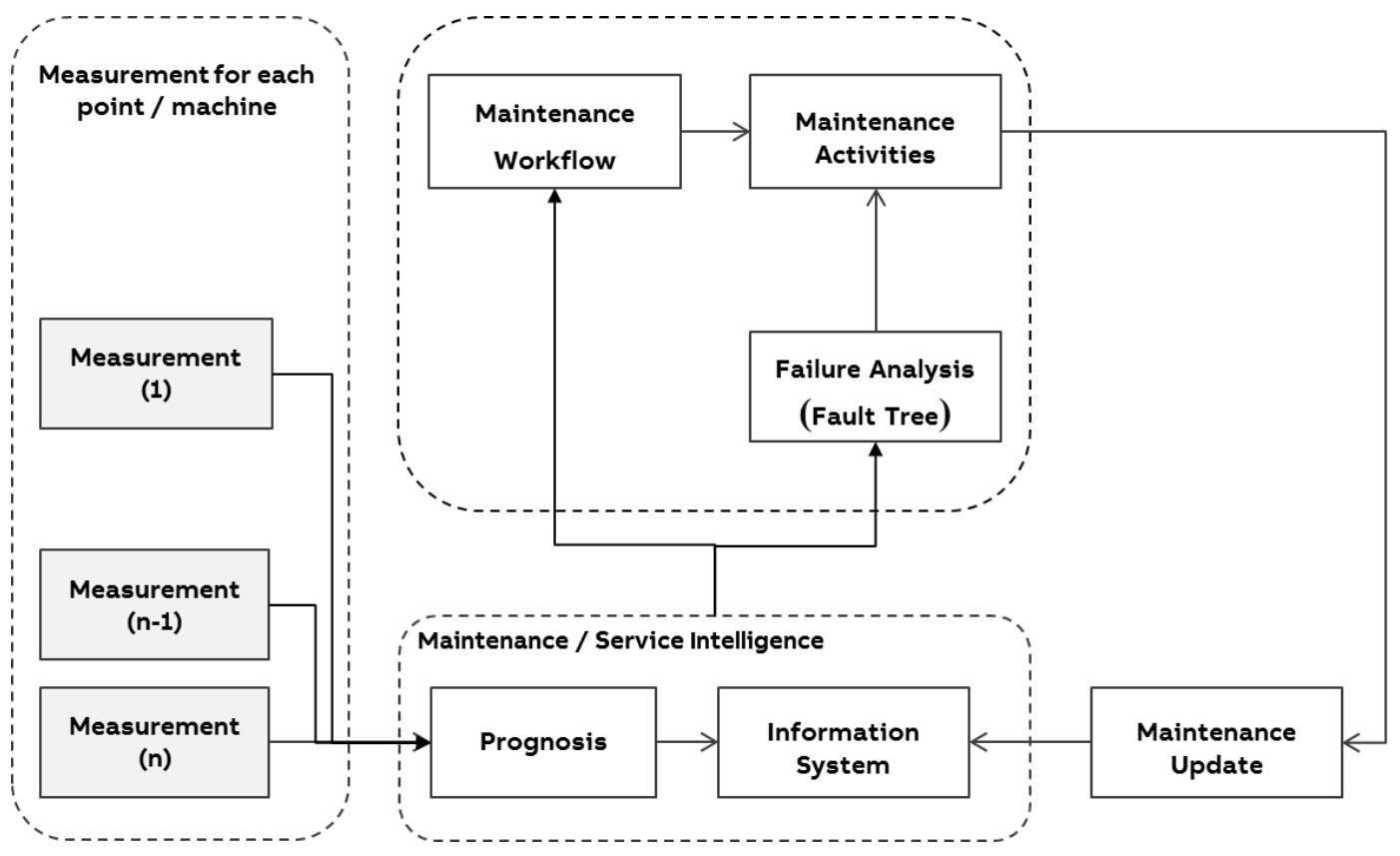

Figure 3. Condition based maintenance for plant-wide fleet monitoring.

\section{Recent Trends in Rotating Machine Fault Diagnostics}

Torque dynamics, torsional oscillations, shaft fatigue, and ageing of other mechanical parts, such as bearings and gearboxes, constitute anomalies internal to the machine, whereas extreme loading or sub synchronous resonance (SSR) mainly constitute anomalies external to the machine. The main areas of investigation in electrical machines condition diagnostics have been:

- Monitoring and distributed control system (DCS) integration,

- Diagnostic algorithms,

- Advanced diagnostic algorithms.

\subsection{Monitoring and Distributed Control System (DCS) Integration}

Integration of condition monitoring and the distributed control system is of crucial importance for better plant observability and operations. As shown in Figure 4, the integration approaches can be of three types: on-equipment, on-premise, and on-cloud. On-equipment integration provides a continuous monitoring of the equipment, and it usually has high update rates from the sensors for diagnostic algorithms.

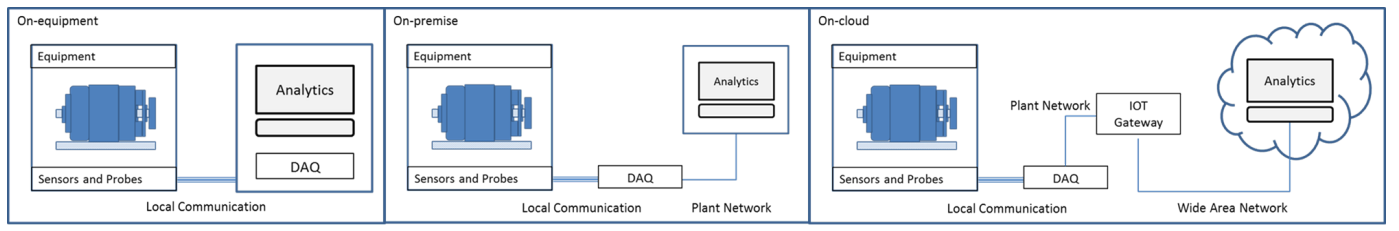

Figure 4. Monitoring system integration in industrial automation.

On-premise integration has a data acquisition unit to collect sensor data and send sensor information to diagnostics running as part of the plant operations. Typically, the data for the diagnostics is transferred using the plant network, and may have data rate limits. However, they offer sufficient computational resources for diagnostic algorithms. On-cloud diagnostics offer elasticity required for the data and computational resources. The cloud solution provides the historian for multi-dimensional data and sophisticated diagnostic algorithms for offline analysis and fault predictions. The equipment 
diagnostics may demand different resources for update rates, computation, notification mechanisms, and reinitialization. The evolutionary needs are improvement of diagnostics with an easy retrofit, augmentation of new methods for better fault diagnosis, error detection using newly invented techniques, and supporting systems. A general overview of diagnostic algorithms is given with an example of induction machine diagnostics. In addition, new diagnostic methods using digital signal processing and expert systems based on artificial intelligence are included. Still, the major challenge in automation system is scaling the system diagnostic abilities without losing the existing industrial practices. Automation system architecture uses a suitable integration method and it depends on the type of monitoring such as continuous versus offline, along with the diagnostic algorithms and maintenance trigger mechanisms.

\subsection{Diagnostic Algorithms}

In 2003, a literature survey was conducted and reported [18] to reflect the state-of-the-art development in this important area. The report points out the potential benefits through the utilization of advanced signal processing and artificial intelligence techniques in developing novel condition monitoring schemes. Rotating machines often run under a hostile operating environment, with possible uneven loading and overloading. Although precision processes govern the manufacturing of motors, any small but finite tolerance overrun leads to growing deterioration as time passes, resulting in eccentricities, torsional stress and other variants of stresses on the rotors, stators, gearbox, and other associated components that eventually will lead to their failures. Even the natural aging processes of the motor components get accelerated under unfavourable operating conditions. The magnetic coupling between the stator and rotor makes them work in coordination, and any anomaly to this coordinated work means that any malfunctioning of the rotors would continuously impact the working of the stator and vice versa. The most commonly used motors in the industry are induction motors, due to their robustness, ruggedness, reliability, efficiency, and low price. In this section, the induction motor is considered as an example to illustrate the recent developments in the machine diagnostics and monitoring applications. A similar approach is extended to other machines for their diagnostics on their specific parameters, such as torque ripples due to commutation in direct current (DC) machines, to manifest mechanical and electrical anomalies of the machines. Specific anomalies in rotating machines with industrial loads can be broadly categorized as listed below:

- Inter-turn short or open circuit in stator winding,

- Rotor eccentricities,

- Broken rotor bar or cracked rotor end rings,

- Static and/or dynamic air gap irregularities,

- Bent shaft (in the case of machine fleet),

- Bent shaft (fleet of turbine in case of utility),

- Shorted rotor field winding,

- Bearing and gearbox failures,

- Extremities of electrical loading and their dynamics (utilities),

- Extremities of mechanical loading and their dynamics (process plants),

- Interplay between electrical and mechanical counterparts (SSR).

Further refinement of the above list of anomalies leads to three broad categories of anomalies viz., the anomalies originating out of progressive mechanical defects, progressive electrical defects and lastly their coexistence and interplay. In an industrial application, such defects result in unscheduled maintenance leading to production loss and overall productivity reduction. Rotor failures seem to be the most common failures. Hence, development of rotor performance monitoring sensor, which works in a constrained environment is critical to the deployment of advanced techniques. Rotor failures may reflect in the motor performance by way of imbalance and modulation of stator current, heating, torque and speed ripple, increased losses, and decreased average torque leading to reduced efficiency. Stator current measurement, extraction of current signatures, and its analysis have 
evolved as a means to detect some rotor defects without rotor-based sensors. The most recent research work is aimed at electrical monitoring of the motor based on the use of electrical-signature-analysis techniques, with emphasis on inspecting its stator current [19-27]. Lower and upper sideband current assessment may not be a good solution, as it is hard to extract sidebands around the main frequency [28]. Therefore, it may be essential to develop different types of signal processing techniques $[21,26,27,29,30]$, artificial intelligence (AI) [25,31,32] and parameter estimation [33] methods to be used in condition monitoring applications. Multiple voltage and current inputs enable computation and generation of derived data including space-vector current, air-gap torque, different instantaneous powers, etc., [23,34]. Similarly, signature analyses of the current Park's vector modulus [35,36], torque [34], single-phase power, partial, and total instantaneous active powers [37] have been proposed. These new techniques seem to be as effective as signature analysis when using only the line current [38]. The use of instantaneous reactive power has been shown for broken-rotor-bar diagnosis in three-phase induction motors [39].

Stator windings and their insulation system constitute the second potential source of failures since the various stresses that act on the motor cause gradual deterioration of stator insulation. Short-circuit and open-circuit of stator windings, and magnetic core failures are the failure modes associated with the stator. Coil-to-coil short circuit, phase-to-phase short circuit, and phase-to-ground short circuit variants are consequences of insulation failure, often due to a combination of temperature rise, mechanical and electric stress. On the other hand, open-circuit defects are comparatively rare and advantageously have a longer lead time to failures. Various surveys on motor reliability have been carried out over the years, and it is reported that the percentage of motor failures due to problems with the insulation is about $26 \%$ [40-42] or even $36 \%$ [43]. A turn-to-turn failure will eventually lead to complete failure of the winding, and the latency involved in this progression is unknown and hard to determine; therefore, online diagnostic techniques to detect turn-to-turn faults within a coil at an incipient stage may be needed $[22,44]$.

The detection of stator winding faults has been reported as based on the analysis of vibration, axial leakage flux and stray flux, and these methods require the installation of sensors that may be infeasible or costly [39]. A non-invasive technique based on spectral analysis of motor current and winding temperature has been introduced to detect asymmetries of the machine. Currents may be transformed prior to analysis, e.g., by Park's transformation. Inter-turn fault detection through monitoring the presence of certain rotor-slot residual saturation and related terminal voltage harmonics is suggested. A spectral analysis based technique for diagnosis of both the rotor and stator winding faults is addressed. Specifically, signature based analysis of instantaneous active and reactive power obtained from the measured current and voltages has been carried out to detect stator winding faults. This method has been found to distinguish problems well from load torque oscillations and from other abnormalities that manifest identical behaviour. As far as the core failures, they are irreversible and they warrant the removal of motor from service [39].

\subsection{Advanced Diagnostic Algorithms}

The feasibility of digital signal processing (DSP) as part of analytics has triggered innovation in machine diagnostics. The signal processing has usually stringent requirements on the sensor data acquisition and update rates for accurate prediction of faults. Digital signal processing techniques for diagnostics are broadly classified as non-parametric, parametric, and high-resolution spectrum analysis methods.

Non-parametric are classical methods that begin by estimating the autocorrelation sequence from a given data, followed by the estimation of the power spectrum by employing a Fourier Transform. The Fast Fourier Transform (FFT) is computationally efficient and can give rise to a conceptually simple motor current signature analyzer (MCSA) [45]. On the other hand, in parametric methods, a process model is selected using sufficient prior knowledge and then model parameters are estimated from the process data. Finally, an estimation of the power spectrum is performed using the 
calculated parameters. The commonly used models are autoregressive (AR), moving average (MA), and autoregressive moving average (ARMA). Since the estimated parameters are small in number, it would be more efficient to transmit or store these parameters instead of signal values. The signal would be then reconstructed from the parameters. However, there are several applications such as steel rolling mills and cement industry processes where the operating point of the machine is not constant. This leads to the current, voltage, and power signals to be highly dynamic. Such non-stationary signals are handled by using short time Fourier transforms (STFTs). The use of STFTs and pattern-recognition techniques to detect faults in induction motors under varying operating conditions have been demonstrated [46]. The application of STFTs assumes stationary signals such as motor speed and load, which may be considered stationary in the analysis window. Accurate identification of frequency related faults can be accomplished by using a finite impulse response (FIR) filter bank combined with high-resolution spectrum analysis [47]. It corresponds to an eigenvalue analysis of the autocorrelation matrix of the motor current time series signals. The proposed method combines a FIR filter bank with high-resolution spectral analysis based on multiple signal classification for an accurate identification of the frequency-related fault. Results show the methodology potentiality as a deterministic detection technique that is suited for detecting multiple features of fault-related frequencies. For example, the bank of bandpass filters separates the original current and vibration signals into different fault-related bandwidths. Then, a high-resolution spectral analysis is applied to each bandwidth for an accurate identification of the frequency-related fault that identifies the presence of single or combined faults [47].

Another important consideration is wavelet analysis for fault diagnosis. STFTs are used to analyse non-stationary signals in a short signal window. In contrast, wavelet analysis non-stationary signals are simultaneously analysed at different resolutions: a larger window is used to get an estimate of stationary signal dynamics while smaller window is used for the transients. This multi-resolution or multi-scale view of the signal forms the foundation for wavelet analysis [48]. Non-stationary signals also originate out of starting current transients in induction motors. Wavelet analysis enables the detection of faults under no-load condition using the transient starting current of the motor $[49,50]$.

Analytic wavelet transform (AWT) is another algorithm capable of detecting and tracking the fault frequencies. The analytical wavelet ridge detection [51] captures the small amplitude of the signals at the fault frequencies, whereas the phase information from the complex AWT facilitates tracking genuine faulty signals such as faulty stator current. Another example of use of AWT can be found in brushless DC (BLDC) Motor, where it is adapted to detect and track the fault frequencies of rotor faults such as dynamic eccentricity [47].

Another efficient algorithm is the combination of wavelet and power-spectral-density (PSD) techniques. This approach is popular in detecting faults similar to motor eccentricity and broken bars [52,53].

The typical diagnostic algorithms using wavelets, and fault signature in the frequency band interact with supply frequency. Time synchronous averaging (TSA) technique in association with Discrete Wavelet Transform can bring out more distinctive fault detection. Basically, TSA extracts the deterministic component from a signal. It is also shown that the reliability of the fault detection depends on the wavelet function [54].

\subsection{Machine Diagnostics Using Artificial Intelligence}

Artificial Intelligence diagnostic methods are based on learning algorithms: examples include artificial neural nets (ANN), fuzzy logic (FL), neuro-fuzzy techniques, and genetic algorithms (GA) constitute a second set of techniques termed as model independent techniques for condition monitoring. These models do not describe the dynamics and control of the monitored system but view the system as an input-output map.

Air-gap eccentricity and broken rotor bar faults can be detected using Artificial Neural Network (ANN) [32]. A three layered back propagation ANN, which has been trained using 
Levenberg-Marquardt learning algorithm, uses a filtered vibration input signal. The trained NN is validated using known sets of training samples and the the residuals are generated using ANN output and the monitored data. These residuals trigger the fault indications depending on set residual thresholds. Similarly, the learning algorithms such as clustering techniques are used in combination with ANN. Moreover, it has been shown that ant behaviour based techniques implement clustering methods similar to K-means clustering for evaluation criterion [55]. It has been shown that both the electrical and the mechanical faults can be detected using Self Organizing Map (SOM) based Radial Basis Function (RBF) neural network along with its training algorithm. The SOM learning algorithm facilitates the design of the best possible network architecture according to the input data, and, by the very nature of the RBF neuron, it supports not only the fault detection but also its severity [56].

Fuzzy logic based techniques are another area of AI used mainly in condition based maintenance. Adaptive neuro-fuzzy inference systems (ANFISs), wavelet fuzzy logic wavelet packet transform, state vector machine (SVM), etc, are some of the intelligence building algorithms successfully demonstrated in machine fault predictions. ANFIS is trained using machine historical failure data, while the fault growth model is developed using trained ANFIS whose modeling noise manifests an higher order Markov model. A high-order particle filter uses this Markov model to predict the time evolution of the fault indicator in the form of a probability density function.

Another technique called Wavelet Fuzzy Logic uses a set of health condition states that constitute patterns. These patterns are mapped onto linguistic variables, which are, in turn, mapped to a fuzzy set by a set of membership functions. By means of the defined rule base, it is possible to map every set of health condition states onto one or more fuzzy logic based classification.

Wavelet Packet Transform (WPT) as an extension of the wavelet transform uses redundant basis functions and, hence, can provide an arbitrary time-frequency resolution over all frequency regions [57]. This enables the extraction of features from signals that combines stationary and non-stationary characteristics. The output of the WPT is used by the fuzzy logic functional block to generate the feature vector, which is then normalized and stored as a pattern from the experimental data. When the machine is in operation, the fault is classified comparing the feature vector extracted from real-time data with the stored patterns. As the WPT technique is an effective feature extractor, it can also be used along with support vector machine (SVM). This combination is proven for fault detection, severity assessment and detection of compound faults with high accuracy [58,59].

\section{Plant-Wide Condition Monitoring}

A typical deployment of a condition monitoring system consists of data acquisition (DAQ) unit, a local processing unit constantly communicating with the analytics [60]. Even though various advanced diagnostic methods like signature based techniques for the analysis of stator current and vibration signals are available in the literature, real life implementations of such methods are not numerous. The main reason is the overall commissioning and installation costs. Each DAQ unit is able to support a limited number of diagnostic algorithms and, therefore, in order to achieve a thorough plant condition monitoring, many units are required together with specialized sensors connected by means of proper cables and communication protocols [61]. Since DAQs are high performing and thus expensive, deployment cost rises significantly. The accuracy reached by these units in terms of condition monitoring is satisfactory, but, on the other hand, it is not sufficient to justify such high investment cost.

Therefore, the tendency is to monitor only a subset of the machines, and only very few physical parameters are tracked due to cost constraints. Needless to say, more economical solutions monitoring all machines' parameters are desirable. Even though cost reduction and plant-wide machine monitoring seem to go in opposite directions, with the use of latest low cost technology developments, it is possible to satisfy both of them [17]. In fact, low cost devices integrated with monitored machines can be built: they are miniaturized and more computationally powerful versions of the previous DAQ units, implementing various diagnostic algorithms at the same time and relying on board-integrated 
sensors. Clearly, these monitoring devices are significantly cheaper and can be mounted on the entire machine fleet without relevant economic impact. Unlike DAQs, each of them can track many machine parameters: this may result in reduced monitoring accuracy, since low cost technology may not be high performing, but the lower accuracy may be compensated by the overall plant overview given by machine fleet monitoring. The new integrated devices are able to perform first level analytics on retrieved data, but, in order to achieve deeper inference, constant communication with the remote service monitoring unit is required. Such communication needs to be standard-regulated, since various monitoring devices will be connected; even more importantly, it must meet the real-time requirements. Hence, it is necessary to adopt an integrated approach when we build the deployment architecture: distributed resource sharing, algorithms fusion and computational optimization are the key elements to consider along with the use of low-cost sensing, communication and computation devices.

The literature shows the implementation of intellectual property (IP) cores to enable hardware implementation of diagnostic algorithms [62], but they are not still practical yet. Smart sensor development and low cost continuous monitoring are ongoing research activities: the intended outcome is to offer low-cost, accurate and reliable monitoring sensors [63]. Some of the early work related to modelling and sensing are addressed [64-66]. The most recent development of plant-wide condition monitoring is the use of MEMS based smart sensors and low cost continuous monitoring system, for example: integrated sensing (vibration, temperature, acoustic, and magnetic sensors), communication, and a processing unit embedded with the motor. However, the remaining challenge is combining the state-of-the-art diagnostic algorithms in low cost computing platforms. The hardware platform using field programmable gate arrays (FPGA) seems to be promising, although not matured. A more elaborate research for the incipient detection of multiple faults along with an FPGA based implementation is presented in [67]. It employs the paradigm of information entropy and fuzzy logic. Again, these platforms have to be evaluated for their power consumption, footprint, etc., to make them usable for plant-wide monitoring.

Even though, to a good extent, the deployment of the CM system for individual machines might get duplicated in a meaningful manner, there are exceptions. The main areas of investigation for cost effective plant-wide condition monitoring are:

- Integration of sensing, computing and communication,

- Integrated monitoring, maintenance and service,

- Reliability and failure prediction performance,

- $\quad$ Shared and distributed platform, reduced overall cost per monitoring point.

In the process industry, a condition monitoring system is typically deployed along with the assessment of the risk associated with machine failure [68]. A common plant-wide automation system consists of hierarchically distributed monitoring modules, which are either integrated or embedded within the machines and are interconnected using wired or wireless industrial communication protocols. The information collected by diagnostic sensors is decomposed in order to be processed stepwise. Locally acquired data, such as vibration data from the device accelerometers, are first processed by the embedded device. Then, this processed information is sent to the plant controller or on-premise analytics operations. The information shared with other devices and/or controllers and/or analytics may get processed at each of these stages, enabling computation and communication load distribution. Afterwards, such processed information or objects are gradually aggregated and eventually used in decision support system or Service Intelligence Unit (SIU). The SIU, in turn, aggregates information or objects related to all the machines of the plant to perform overall predictive analysis.

The plant-wide deployment can be carried out using different architectures. Information flow and computation allocation are scheduled using a CM configuration engineering tool. Figure 5 shows a typical deployment using smart sensors. It usually includes an engineering tool, an on-premise operation server, a cloud enabled service or a remote service intelligence unit to support the embedded monitoring of plant-wide equipment. These monitoring devices are connected either to an input-output 
(IO) network or to a control network belonging to automation hierarchy. Furthermore, the information flow is established using a suitable standard communication protocols. Engineering tools are used to configure the monitoring devices embedded in the monitored equipment. An instance of these smart sensors together with an association to the respective monitored machine is created [69]. Configuration information is shared among all the devices of the automation system, including controllers, operation servers, etc. This common configuration is further used in the analytics to develop the predictive diagnostics associated with these individually monitored machines. The SIU further integrates this information for generating the predictive diagnostics and maintenance report across the connected plants.

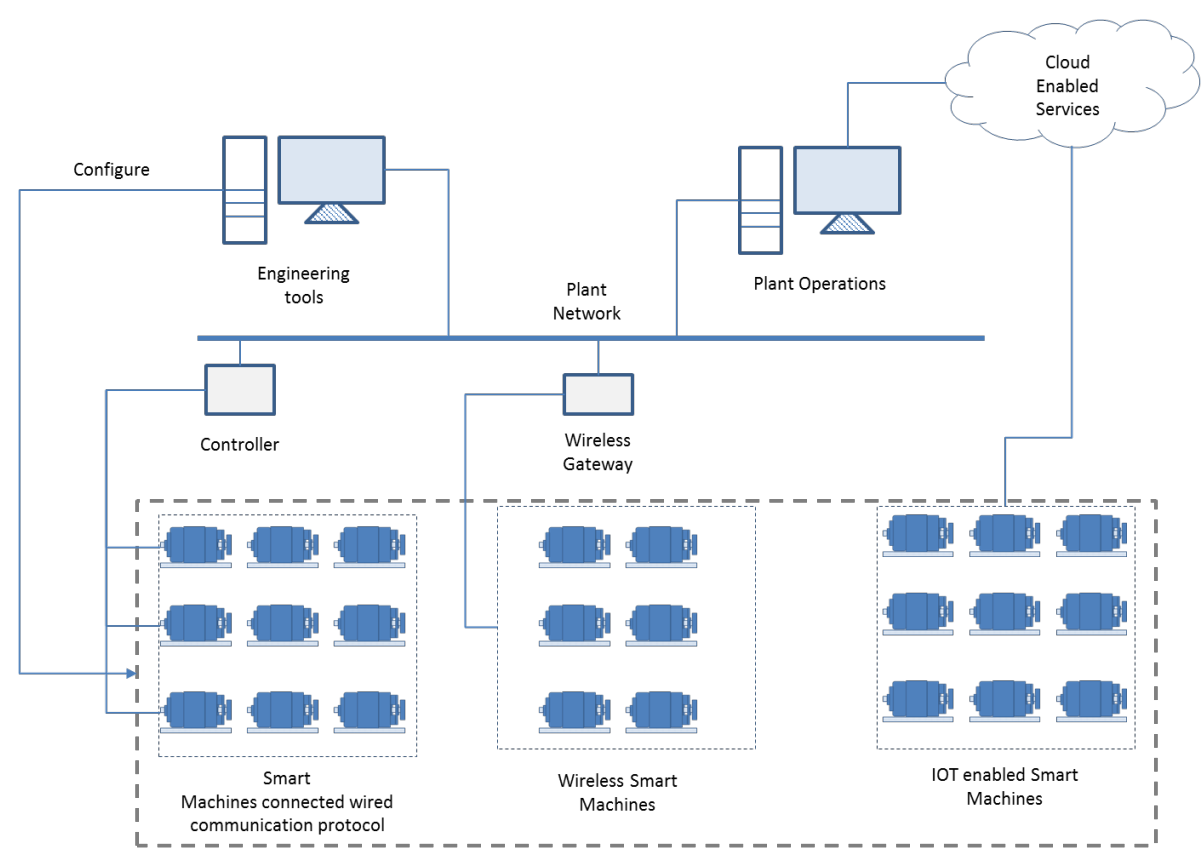

Figure 5. Plant-wide fleet condition monitoring.

The communication and processing requirements depend on the diagnostic application itself, its parameters and the number of machines being monitored in the plant. The recent advances in big data analytics help in handling the large amount of data and processing load. In general, a selected combination of application, sensors information, and maintenance activities are integrated in the service intelligence unit [70]. Several organizations have already matured smart condition monitoring for the entire fleet of machines in a plant, such as smart sensor solutions for plant-wide low voltage motor monitoring.

\section{Conclusions}

Condition monitoring of rotating electrical machines has evolved with the advent of sensing, machine diagnostic methods, data analytics platforms, communication and information management. Developments in these technologies now give a fresh opportunity to obtain automation and monitoring systems suited to diverse plant deployment scenarios that would not previously have been possible. The paper reviews the deployment methods in practice that allow integration of monitoring system on premise, on cloud, and even rogue internet of things (IOT) devices in industrial automation systems. The reviewed methods and techniques may need further analysis for adjacent technologies related to security. The security-enhanced, low-cost, and large-scale deployment is key to a future condition monitoring automation system for rotating electrical machines. 
Acknowledgments: Authors would like to thank ABB., particularly Marco Sanguineti for the support and related discussions. Authors fully acknowledge the useful discussions with ABB colleagues Cajetan T.Pinto, Christopher Ganz, Stefan U. Svensson, and B S Nagabhushana from BMS college of Engineering, Bangalore.

Author Contributions: Mallikarjun Kande performed the literature review, wrote most of the text, and composed the diagrams. Alf J. Isaksson and Rajeev Thottappillil gave suggestions and guidance through project meetings, other discussion and proofreading. Nathaniel Taylor guided the work in regular meetings, and wrote or edited some parts of the text.

Conflicts of Interest: The authors declare no conflict of interest.

\section{References}

1. Kohler, J.L.; Sottile, J.; Trutt, F.C. Condition-based maintenance of electrical machines. In Proceedings of the Conference Record of the 1999 IEEE Industry Applications Conference, Thirty-Forth IAS Annual Meeting, Phoenix, AZ, USA, 3-7 October 1999; Volume 1, pp. 205-211.

2. Bram de Jonge, R.T.; Tinga, T. The influence of practical factors on the benefits of condition-based maintenance over time-based maintenance. Reliab. Eng. Syst. Saf. 2017, 158, 21-30.

3. Minou, C.A.; Olde Keizer, S.D.P.F.; Teunter, R.H. Condition-based maintenance policies for systems with multiple dependent components: A review. Eur. J. Oper. Res. 2017, 261, 405-420.

4. Walker, M. The Diagnosing of Troubles in Electrical Machines; Longmans Green and Co.: Harlow, UK, 1921; pp. 1-20.

5. Foster, G.B. Recent Developments in Machine Vibration Monitoring. IEEE Trans. Ind. Gen. Appl. 1967, IGA-3, 149-158.

6. Kurtz, M.; Stone, G.C. Partial discharge testing of generator insulation. In Proceedings of the 1978 IEEE International Conference on Electrical Insulation, Philadelphia, PA, USA, 12-14 June 1978; pp. 73-77.

7. Timperley, J.E. Incipient Fault Identification Through Neutral RF Monitoring of Large Rotating Machines. IEEE Trans. Power Appar. Syst. 1983, PAS-102, 693-698.

8. Harrold, R.T.; Emery, F.T. Radio Frequency Diagnostic Monitoring of Electrical Machines. IEEE Electr. Insulation Mag. 1986, 2, 18-24.

9. Kwan, C.; Ayhan, B.; Yin, J.; Liu, X.; Ballal, P.; Athamneh, A.; Ramani, A.; Lee, W.; Lewis, F. Real-time system condition monitoring using wireless sensors. In Proceedings of the 2009 IEEE Aerospace Conference, Big Sky, MT, USA, 7-14 March 2009; pp. 1-8.

10. Amaro, J.P.; Ferreira, F.J.T.E.; Cortesão, R.; Vinagre, N.; Bras, R.P. Low cost wireless sensor network for in-field operation monitoring of induction motors. In Proceedings of the 2010 IEEE International Conference on Industrial Technology, Vina del Mar, Chile, 14-17 March 2010; pp. 1044-1049.

11. Bratthall, L.G.; van der Geest, R.; Hofmann, H.; Jellum, E.; Korendo, Z.; Martinez, R.; Orkisz, M.; Zeidler, C.; Andersson, J.S. Integrating hundred's of products through one architecture-The industrial IT architecture. In Proceedings of the 24th International Conference on Software Engineering (ICSE 2002), Orlando, FL, USA, 19-25 May 2002; pp. 604-614.

12. Kolacinski, R.M.; Theeranaew, W.; Loparo, K.A. An information-theoretic architecture for advanced condition monitoring and control of power generating plants. In Proceedings of the 2012 Future of Instrumentation International Workshop (FIIW), Gatlinburg, TN, USA, 8-9 October 2012; pp. 1-4.

13. Vasel, J. One plant, one system: Benefits of integrating process and power automation. In Proceedings of the 65th Annual Conference for Protective Relay Engineers, College Station, TX, USA, 2-5 April 2012; pp. 215-250.

14. Loutfi, M.Y. Online condition monitoring network for critical equipment at Holcim's STE. genevieve plant. In Proceedings of the 2011 IEEE-IAS/PCA 53rd Cement Industry Technical Conference, St. Louis, MO, USA, 22-26 May 2011; pp. 1-11.

15. Simon, C.; Theilliol, D.; Sauter, D.; Orkisz, M. Remaining useful life assessment via residual generator approach-A SOH virtual sensor concept. In Proceedings of the 2014 IEEE Conference on Control Applications (CCA), Antibes/Nice, France, 8-10 October 2014; pp. 1202-1207.

16. Abu-Rub, H.; Bayhan, S.; Moinoddin, S.; Malinowski, M.; Guzinski, J. Medium-Voltage Drives: Challenges and existing technology. IEEE Power Electron. Mag. 2016, 3, $29-41$. 
17. Orkisz, M.; Wnek, M.; Kryczka, K.; Joerg, P. Variable frequency drive as a source of condition monitoring data. In Proceedings of the 2008 International Symposium on Power Electronics, Electrical Drives, Automation and Motion, Ischia, Italy, 11-13 June 2008; pp. 179-183.

18. Han, Y.; Song, Y.H. Condition monitoring techniques for electrical equipment-A literature survey. IEEE Trans. Power Deliv. 2003, 18, 4-13.

19. Bonnett, A.H.; Soukup, G.C. Rotor Failures in Squirrel Cage Induction Motors. IEEE Trans. Ind. Appl. 1986, IA-22, 1165-1173.

20. Milimonfared, J.; Kelk, H.M.; Nandi, S.; Minassians, A.D.; Toliyat, H.A. A novel approach for brokenrotor-bar detection in cage induction motors. IEEE Trans. Ind. Appl. 1999, 35, 1000-1006.

21. Benbouzid, M.E.H.; Kliman, G.B. What stator current processing-based technique to use for induction motor rotor faults diagnosis? IEEE Trans. Energy Convers. 2003, 18, 238-244.

22. Nandi, S.; Toliyat, H.A.; Li, X. Condition monitoring and fault diagnosis of electrical motors-A review. IEEE Trans. Energy Convers. 2005, 20, 719-729.

23. Eltabach, M.; Charara, A.; Zein, I. A comparison of external and internal methods of signal spectral analysis for broken rotor bars detection in induction motors. IEEE Trans. Ind. Electron. 2004, 51, 107-121.

24. Kliman, G.B.; Koegl, R.A.; Stein, J.; Endicott, R.D.; Madden, M.W. Noninvasive detection of broken rotor bars in operating induction motors. IEEE Trans. Energy Convers. 1988, 3, 873-879.

25. Filippetti, F.; Franceschini, G.; Tassoni, C.; Vas, P. Recent developments of induction motor drives fault diagnosis using AI techniques. IEEE Trans. Ind. Electron. 2000, 47, 994-1004.

26. Kia, S.H.; Henao, H.; Capolino, G.A. A High-Resolution Frequency Estimation Method for Three-Phase Induction Machine Fault Detection. IEEE Trans. Ind. Electron. 2007, 54, 2305-2314.

27. Bellini, A.; Filippetti, F.; Franceschini, G.; Tassoni, C.; Kliman, G.B. Quantitative evaluation of induction motor broken bars by means of electrical signature analysis. IEEE Trans. Ind. Appl. 2001, 37, 1248-1255.

28. Arthur, N.; Penman, J. Induction machine condition monitoring with higher order spectra. IEEE Trans. Ind. Electron. 2000, 47, 1031-1041.

29. Jung, J.H.; Lee, J.J.; Kwon, B.H. Online Diagnosis of Induction Motors Using MCSA. IEEE Trans. Ind. Electron. 2006, 53, 1842-1852.

30. Bellini, A. Quad Demodulation: A Time-Domain Diagnostic Method for Induction Machines. IEEE Trans. Ind. Appl. 2009, 45, 712-719.

31. Ayhan, B.; Chow, M.Y.; Song, M.H. Multiple Discriminant Analysis and Neural-Network-Based Monolith and Partition Fault-Detection Schemes for Broken Rotor Bar in Induction Motors. IEEE Trans. Ind. Electron. 2006, 53, 1298-1308.

32. Su, H.; Chong, K.T. Induction Machine Condition Monitoring Using Neural Network Modeling. IEEE Trans. Ind. Electron. 2007, 54, 241-249.

33. Bazine, I.B.A.; Tnani, S.; Poinot, T.; Champenois, G.; Jelassi, K. On-line detection of stator and rotor faults occurring in induction machine diagnosis by parameters estimation. In Proceedings of the 8th IEEE Symposium on Diagnostics for Electrical Machines, Power Electronics Drives, Bologna, Italy, 5-8 September 2011; pp. 105-112.

34. Kral, C.; Wieser, R.S.; Pirker, F.; Schagginger, M. Sequences of field-oriented control for the detection of faulty rotor bars in induction machines-the Vienna Monitoring Method. IEEE Trans. Ind. Electron. 2000, $47,1042-1050$.

35. Cardoso, A.J.M.; Cruz, S.M.A.; Carvalho, J.F.S.; Saraiva, E.S. Rotor cage fault diagnosis in three-phase induction motors, by Park's vector approach. In Proceedings of the Industry Applications Conference, Thirtieth IAS Annual Meeting, IAS '95, Conference Record of the 1995 IEEE, Orlando, FL, USA, 8-12 October 1995; Volume 1, pp. 642-646.

36. Aboubou, A.; Sahraoui, M.; Zouzou, S.E.; Razik, H.; Rezzoug, A. Broken bars and/or end rings detection in three-phase induction motors by the extended Park's vector approach. In Proceedings of the 9th IEEE International Power Electronics Congress (CIEP 2004), Celaya, Gto., Mexico, 17-22 October 2004; pp. 128-133.

37. Zagirnyak, M.; Mamchur, D.; Kalinov, A. Induction motor diagnostic system based on spectra analysis of current and instantaneous power signals. In Proceedings of the IEEE SOUTHEASTCON 2014, Lexington, KY, USA, 13-16 March 2014; pp. 1-7. 
38. Drif, M.; Cardoso, A.J.M. The instantaneous power factor approach for rotor cage faults diagnosis in three-phase induction motors. In Proceedings of the 2008 International Symposium on Power Electronics, Electrical Drives, Automation and Motion, Ischia, Italy, 11-13 June 2008; pp. 173-178.

39. Drif, M.; Cardoso, A.J.M. Stator Fault Diagnostics in Squirrel Cage Three-Phase Induction Motor Drives Using the Instantaneous Active and Reactive Power Signature Analyses. IEEE Trans. Ind. Inform. 2014, 10, 1348-1360.

40. Bell, R.N.; Mcwilliams, D.W.; O’Donnell, P.; Singh, C.; Wells, S.J. Report of Large Motor Reliability Survey of Industrial and Commercial Installations, Part I. IEEE Trans. Ind. Appl. 1985, IA-21, 853-864.

41. Bell, R.N.; Heising, C.R.; O’Donnell, P.; Singh, C.; Wells, S.J. Report of Large Motor Reliability Survey of Industrial and Commercial Installations, Part II. IEEE Trans. Ind. Appl. 1985, IA-21, 865-872.

42. O'Donnell, P.; Heising, C.; Singh, C.; Wells, S.J. Report of Large Motor Reliability Survey of Industrial and Commercial Installations: Part 3. IEEE Trans. Ind. Appl. 1987, IA-23, 153-158.

43. Thorsen, O.V.; Dalva, M. A survey of faults on induction motors in offshore oil industry, petrochemical industry, gas terminals, and oil refineries. IEEE Trans. Ind. Appl. 1995, 31, 1186-1196.

44. Siddique, A.; Yadava, G.S.; Singh, B. A review of stator fault monitoring techniques of induction motors. IEEE Trans. Energy Convers. 2005, 20, 106-114.

45. Orman, M.; Orkisz, M.; Pinto, C.T. Slip estimation of a large induction machine based on MCSA. In Proceedings of the 8th IEEE Symposium on Diagnostics for Electrical Machines, Power Electronics Drives, Bologna, Italy, 5-8 September 2011; pp. 568-572.

46. Yazici, B.; Kliman, G.B. An adaptive statistical time-frequency method for detection of broken bars and bearing faults in motors using stator current. IEEE Trans. Ind. Appl. 1999, 35, 442-452.

47. Garcia-Perez, A.; de Jesus Romero-Troncoso, R.; Cabal-Yepez, E.; Osornio-Rios, R.A. The Application of High-Resolution Spectral Analysis for Identifying Multiple Combined Faults in Induction Motors. IEEE Trans. Ind. Electron. 2011, 58, 2002-2010.

48. Vetterli, M.; Herley, C. Wavelets and filter banks: Theory and design. IEEE Trans. Signal Process. 1992, 40, 2207-2232.

49. Burnett, R.; Watson, J.F.; Elder, S. The application of modern signal processing techniques to rotor fault detection and location within three phase induction motors. In Proceedings of the Integrating Intelligent Instrumentation and Control Instrumentation and Measurement Technology Conference (IMTC/95.), Waltham, MA, USA, 23-26 April 1995.

50. Eren, L.; Devaney, M.J. Motor bearing damage detection via wavelet analysis of the starting current transient. In Proceedings of the 18th IEEE Instrumentation and Measurement Technology Conference (IMTC 2001), Budapest, Hungary, 21-23 May 2001; Volume 3, pp. 1797-1800.

51. Rajagopalan, S.; Aller, J.M.; Restrepo, J.A.; Habetler, T.G.; Harley, R.G. Analytic-Wavelet-Ridge-Based Detection of Dynamic Eccentricity in Brushless Direct Current (BLDC) Motors Functioning Under Dynamic Operating Conditions. IEEE Trans. Ind. Electron. 2007, 54, 1410-1419.

52. CusidÓCusido, J.; Romeral, L.; Ortega, J.A.; Rosero, J.A.; Espinosa, A.G. Fault Detection in Induction Machines Using Power Spectral Density in Wavelet Decomposition. IEEE Trans. Ind. Electron. 2008, 55, 633-643.

53. Gu, F.; Wang, T.; Alwodai, A.; Tian, X.; Shao, Y.; Ball, A. A new method of accurate broken rotor bar diagnosis based on modulation signal bispectrum analysis of motor current signals. Mech. Syst. Signal Process. 2015, 50, 400-413.

54. Ngote, N.; Guedira, S.; Ouassaid, M.; Cherkaoui, M. Comparison of wavelet-functions for induction-motor rotor fault detection based on the hybrid Time Synchronous Averaging-Discrete Wavelet Transform approach. In Proceedings of the 2015 International Conference on Electrical and Information Technologies (ICEIT), Marrakech, Morocco, 25-27 March 2015; pp. 94-99.

55. Soualhi, A.; Clerc, G.; Razik, H. Detection and Diagnosis of Faults in Induction Motor Using an Improved Artificial Ant Clustering Technique. IEEE Trans. Ind. Electron. 2013, 60, 4053-4062.

56. Wu, S.; Chow, T.W.S. Induction machine fault detection using SOM-based RBF neural networks. IEEE Trans. Ind. Electron. 2004, 51, 183-194.

57. Escamilla-Ambrosio, P.J.; Liu, X.; Lieven, N.A.J.; Ramírez-Cortés, J.M. Wavelet-fuzzy logic approach to structural health monitoring. In Proceedings of the 2011 Annual Meeting of the North American Fuzzy Information Processing Society, El Paso, TX, USA, 18-20 March 2011; pp. 1-6. 
58. Zhong, J.; Yang, Z.; Wong, S.F. Machine condition monitoring and fault diagnosis based on support vector machine. In Proceedings of the 2010 IEEE International Conference on Industrial Engineering and Engineering Management, Macao, China, 7-10 December 2010; pp. 2228-2233.

59. Sun, L.; Liu, M.; Qian, H.; Qiao, C. A New Method to Mechanical Fault Classification with Support Vector Machine. In Proceedings of the 2011 2nd International Conference on Digital Manufacturing Automation, Hunan, China, 5-7 August 2011; pp. 68-73.

60. Sheng, Z.; Liu, Z.; Wang, J.; Lu, Y. Development and application of condition monitoring system for plant production. In Proceedings of the 24th Chinese Control and Decision Conference (CCDC), Taiyuan, China, 23-25 May 2012; pp. 2490-2493.

61. Cardoso, F.J.A.; Faria, S.P.S.; Oliveira, J.E.G. A smart sensor for the condition monitoring of industrial rotating machinery. In Proceedings of the 2012 IEEE Sensors, Taipei, Taiwan, 28-31 October 2012; pp. 1-4.

62. Cabal-Yepez, E.; Osornio-Rios, R.A.; Romero-Troncoso, R.J.; Razo-Hernandez, J.R.; Lopez-Garcia, R. FPGA-Based Online Induction Motor Multiple-Fault Detection with Fused FFT and Wavelet Analysis. In Proceedings of the 2009 International Conference on Reconfigurable Computing and FPGAs, Quintana Roo, Mexico, 9-11 December 2009; pp. 101-106.

63. Wildermuth, S.; Ahrend, U.; Byner, C.; Rzeszucinski, P.; Lewandowski, D.; Orman, M. Condition monitoring of electric motors based on magnetometer measurements. In Proceedings of the 2015 IEEE 20th Conference on Emerging Technologies Factory Automation (ETFA), Luxembourg, 8-11 September 2015; pp. 1-4.

64. Stein, J.L.; Park, Y. Modeling and Sensing Issues for Machine Diagnostics. In Proceedings of the 1988 American Control Conference, Atlanta, GA, USA, 15-17 June 1988; pp. 1924-1930.

65. Su, C.Q. Smart condition monitoring. In Proceedings of the 2014 IEEE Electrical Insulation Conference (EIC), Philadelphia, PA, USA, 8-11 June 2014; pp. 138-141.

66. Zygmunt, M.; Budyn, M.; Orkisz, M.; Ottewill, J.; Jaramillo, V.; Nowak, A. Visual modeling of condition monitoring systems. In Proceedings of the 2012 IEEE 17th International Conference on Emerging Technologies Factory Automation (ETFA 2012), Krakow, Poland, 17-21 September 2012; pp. 1-4.

67. Romero-Troncoso, R.J.; Saucedo-Gallaga, R.; Cabal-Yepez, E.; Garcia-Perez, A.; Osornio-Rios, R.A.; Alvarez-Salas, R.; Miranda-Vidales, H.; Huber, N. FPGA-Based Online Detection of Multiple Combined Faults in Induction Motors Through Information Entropy and Fuzzy Inference. IEEE Trans. Ind. Electron. 2011, 58, 5263-5270.

68. Wasif, H.; Aboutalebi, A.; Brown, D.; Axel-Berg, L. Condition monitoring system for process industries a business approach. In Proceedings of the 2012 IEEE Symposium on Industrial Electronics and Applications, Bandung, Indonesia, 23-26 September 2012; pp. 251-256.

69. Josifovic, A.; Corney, J. Development of industrial process characterisation through data analysis. In Proceedings of the 2016 IEEE Symposium Series on Computational Intelligence (SSCI), Athens, Greece, 6-9 December 2016; pp. 1-7.

70. Xu, B.; Kumar, S.A. Big Data Analytics Framework for System Health Monitoring. In Proceedings of the 2015 IEEE International Congress on Big Data, New York, NY, USA, 27 June-2 July 2015; pp. 401-408.

(C) 2017 by the authors. Licensee MDPI, Basel, Switzerland. This article is an open access article distributed under the terms and conditions of the Creative Commons Attribution (CC BY) license (http:// creativecommons.org/licenses/by/4.0/). 